\section{SCIENCE AND TECHNOLOGY OF POWDER METALLURGY}

Treatise on Powder Metallurgy

By Dr. Claus G. Goetzel. Vol. 1 : Technology of Metal Powders and their Products. Pp. xxvii +778 . 90s. Vol. 2 : Applied and Physical Powder Metallurgy. Pp. xviii +910. 144s. (New York and London: Interscience Publishers, Inc., 1949-50.)

YOMPARATIVELY little is generally known of 1 the increasingly important part played by the products of powder metallurgy in industry. Possibly the publication of this encyclopædic treatise on the subject may conduce to a wider knowledge of the subject, especially in engineering circles. Powder metallurgy is defined as the art of producing metal powders and objects shaped from individual, mixed or alloyed metal powders, with or without the inclusion of non-metallic constituents, by pressing or moulding objects which may be simultaneously or afterwards heated to produce a coherent mass, either without fusion or with fusion of a low-melting constituent only.

The earliest products on a commercial scale were porous oil-impregnated bearings of bronze. To-day the most important materials produced are cemented carbide tools which in a few years have revolutionized the operations of cutting, grinding, machining and milling, and have accelerated production and effected economies beyond any expectation of engineer or manufacturer; at the same time the products of powder metallurgy have suggested solutions to many outstanding problems in the production of hightemperature resistant materials, to mention only one group of potentialities.

The Second World War enormously accelerated progress in every department of powder metallurgy, and workers therein have felt the lack of any comprehensive survey which would correlate theory and practice and at the same time attempt an over-all picture of the development and progress which have been so notable a feature of the past decade. The two volumes by Dr. C. G. Goetzel most admirably fill that void. Vol. 1 covers the technology of the processes of the art, discusses the underlying principles and provides a historical review. Methods of powder production and the characteristics and properties of powders are discussed in detail. Methods of testing powders are described, and attention is given to the widest range of commercial powders. The behaviour of powders under pressure and the moulding of powders into solid form are dealt with, followed by a discussion of dies, punches, presses, and, after consideration of hot pressing, the principles of sintering and its practice, including furnaces and atmospheres as well as finishing treatments. Vol. 2, divided into two parts, deals first with applied powder metallurgy and supplies the fullest account extant of the happenings and progress of the past ten years. The sections cover refractory metals and alloys, hard metals and compositions, electrical and magnetic materials, ferrous and non-ferrous materials for structural parts, porous products, friction materials and dental alloys. The second half of the volume, on physical powder metallurgy, describes and discusses the important phases of the physical metallurgy of metal powders, comparing the physical properties of sintered and fused industrial alloys and metals. An excellent survey is given of sintered metals and alloys for potential industrial use; the stress analysis of sintered metal structure and an appraisal of testing methods provide material of outstanding practical value, while there is a full and most useful review of theories of bonding and sintering.

A section is devoted to the future of powder metallurgy, and it is perhaps the future that should be stressed, for no other technique has such potentialities or holds out such promise as powder metallurgy. Not only does it overcome the handicaps that are inherent in the limitations imposed by the necessity for melting and then cooling-down molten metal, but also it overcomes the incompatibilities arising from widely divergent melting points, large variations in electrical or heat conductivity, and the differences between metallic and non-metallic bodies. It can produce unique materials, and these two volumes by Dr. Goetzel provide a guide and a commentary comparable with the best that is available in any other subject. Moreover, the documentation is of a high order and is to be supplemented by a third volume which will comprise a classified and annoted bibliography covering both literature and patents.

H. W. GREenwood

\section{OPERATIONAL CALCULUS}

\section{Operational Calculus based on the Two-Sided} Laplace Integral

By Dr. Balth van der Pol and Dr. H. Bremmer. Pp. xiii +415 . (Cambridge : At the University Press, 1950.) 55s. net.

A LTHOUGH operational calculus is not derived A from anything fundamentally new in mathematics, it is nevertheless a comparatively modern technique. Since its recognition as a valuable weapon, both in pure mathematics and mathematical physics, much literature has appeared, ranging in scope and manner of presentation from the practical text-book to the erudite treatise. In almost all cases where the analytical background has been worked out in detail, the author has adopted one of two main courses : either following Heaviside in using an operator $1 / p$ defined as a definite integral; or by using the so-

called Laplace transform $\int_{0}^{\infty} \exp (-p t) f(t) d t$, or in some instances $p \int_{0}^{\infty} \exp (-p t) f(t) d t$. It is not intended

here to compare the advantages and disadvantages of these alternatives (which are, of course, mathematically equivalent), but to discuss briefly a third method of attack based on the replacement of the one-sided integral, quoted above, by a two-sided one of similar character, namely, $p \int_{-\infty}^{\infty} \exp (-p t) f(t) d t$.

It is at once clear that this modification of the Laplace transform does not basically affect the ideas and methods of procedure encountered in the one-sided case. We still have, for example, a unique 'image' $\varphi(p)$ derived from the 'original' $f(t)$ by the integral transformation, and a complex inversion-integral enabling us, in certain cases, to determine explicitly the original of a given image. Furthermore, we are still in possession of the fundamental asset of the oper- 